\title{
Analytical measures (tests) recommended before delivery in a labour room for female
}

\begin{abstract}
The study was conducted at central hospital Saidu Sharif, Swat, Khyber Pakhtunkhwa from April to September 2020. A total of 100 pregnant women belonging to different regions of district Swat were examined, prior to delivery in the research study. The age of the studied participants was $20-45$ years. $3 \mathrm{ml}$ of venous blood was taken in a sterile syringe $(3 \mathrm{cc})$ from each woman and drained in EDTA (Ethylene diamine tetra acetate) tube. The tube was immediately carried to Sheikh-Al-Zahid-bin-Haiyan (casualty) hospital's laboratory for complete blood count (CBC), Blood sugar (RBS). Human immunodeficiency virus (HIV), HBS-Ag, Hepatitis C virus (HCV), malarial parasites (MP), Brucella and widal test. Urine was also collected in urine bottles for examination and for COVID-19 detection swab samples were taken from nose of the participants. From the recent study it was concluded that pregnant women in the study are susceptible to many diseases and complications. It was found that $12 \%$ women were severe anemic while $23 \%$ were moderate anemic and $40 \%$ were mild anemic. Covid- 19 was detected in $12 \%$ of the studied women. $2 \%$ were observed as $\mathrm{HCV}$ positive. $10 \%$ of the women had higher blood sugar level (RBS $190 \mathrm{mg} / \mathrm{dl}$ ). $\mathbf{3 5 \%}$ of the studied women had a urinary tract infection (UTI). Only $1 \%$ of the participant was found to be affected by Brucella bacteria. Malarial parasite was found in almost $5 \%$ of the examined participants. HIV was rare and detected in only $1 \%$ of the examined one hundred women.
\end{abstract}

Keywords: pregnancies, brucella bacteria, HCV, HIV, CBC, UTI, RBS
Volume 6 Issue 4 - 202।

\author{
Afzal Khan,' Anwar Ali, ${ }^{2}$ Naseer Ullah,' \\ Kausar Saeed, ${ }^{3}$ Muzafar Shah' \\ 'Centre for Animal Sciences \& Fisheries, University of Swat, \\ Pakistan \\ ${ }^{2}$ Department of Biochemistry, Saidu Medical College, Pakistan \\ ${ }^{3}$ Department of Zoology, University of Buner, Pakistan
}

Correspondence: Muzafar Shah, Centre for Animal Sciences \& Fisheries, University of Swat, Pakistan, Tel +92-3339348044, ORCID 0000-0002-5069-0228, Email muzafar@uswat.edu.pk

Received: June 10,2021 | Published: August 09, 2021

\section{Introduction}

Pregnancy also known as gestation is defined as a period during which one or more offspring develop inside the womb of a women. Normal pregnancy has average gestation time of 38 weeks (9) months. Gestation is generally categorized into 1 st trimester, 2ndtrimester and 3 rd trimester. Each trimester takes a duration of three months. After 38 weeks of gestation normal baby is delivered which is the end of third trimester. To avoid any kind of emergency several diagnostic tests are necessary for pregnant woman before delivery. Different diseases ie Anemia and many other effect both mother and fetus if not recognized before delivery and having both maternal and fetal consequences. The vitamin B 12, folate and iron deficiency are the common causes. The anemia can be diagnosed when the hemoglobin level is less than $11.0 \mathrm{~g} / \mathrm{dl}$ in the third trimester of pregnancy The anemia caused by deficiency of vitamin B 12 occur in $10-28 \%$ of uncomplicated pregnancies. ${ }^{1,2}$

Among the global viral infection HBV infection is the most extensive infection. HBV infected about 2000 million people and approximately 350million are chronic carriers. The world health organization has been recognized high, low middle and low populated geographical areas. Some evaluations of HBs-Ag prevalence have been conducted in greatly endemic countries, where HBs-Ag seroprevalence up to $25 \%$ were detected. Studies of seroprevalence have also been made in Mediterranean countries, which belong to the area of transitional population. In young females the seroprevalence is also particularly noticed therefore in cord-blood specimen and mother the seroprevalence study is important. ${ }^{3,4}$ The placental blood smear and its microscopic studies can evaluate the malarial problems during pregnancy. Due to the presence of WBC and cellular it is difficult to study the placental blood smear an expert technician and good laboratory can evaluate a placental blood smear in a better way. To overcome both the clinical diagnosis and light microscopy test for malaria the WHO repeatedly highlight the urgent need. ${ }^{5,6}$ Objective of the current study to find out the recommended procedures (tests) before delivery in a hospital labour room.

\section{Material and methods}

\section{Study design}

It was research study regarding pre-delivery tests of pregnant women before delivery. The study was conducted at central hospital Saidu Sharif Swat Khyber Pakhtunkhwa from April to September 2020.

\section{Ethical approval}

An ethical approval was compulsory for the study which was granted by the medical ethics committee of the mentioned hospital (Gynaecology and Obstetrics department).

\section{Study participants}

About 100 pregnant women belonging to different regions of district Swat were examined prior to delivery in the research study. Average age of the studied participants was 20-45 years.

\section{Materials}

Surgical gloves, sterile syringes ( $3 \mathrm{cc}$ and $5 \mathrm{cc}$ ), anticoagulants, EDTA (Ethylene diamine tetra acetate) tube, Haematology machine, chemistry analyzer machine (Medonic M32), urine bottles, centrifuge, slides, microscope (light microscope), PCR machine, swab, test tubes, pipette, reagents. 


\section{Clinical and laboratory data collection}

$3 \mathrm{ml}$ of venous blood was taken in a sterile syring (3cc) from each woman and drained in EDTA (Ethylene diamine tetra acetate) tube. The tube was immediately carried to sheikh Al zahid bin Hayan (Casualty) hospital's laboratory for complete blood count (CBC), Blood sugar (RBS), Human immunodeficiency virus (HIV), HBS-Ag, Hepatitis $\mathrm{C}$ virus(HCV), Malarial parasites (MP), Brucella and widal test. Urine was also collected in urine bottles for examination and for COVID-19 detection swab samples were taken from nose of the participants.

\section{Laboratory examination}

Medonic M32 machine was used for complete blood count (CBC), Immunoglobulin G antibody capture particle-adherence test (GACPAT) was used for HIV screening, PCR machine was used for detecting HBS-Ag, COVID-19 and HCV, Brucella and Widal tests were conducted through special kits, for RBS examination microlab m300 was used while for detection of Malarial parasite, slides containing patients' blood smear were examined under the light microscope.

\section{Result}

After completing the research work by examining one hundred pregnant women, the following results were obtained:

\section{Mean hemoglobin}

$12 \%$ percent of the studied women were severe anemic (Hemoglobin $<7 \mathrm{~g} / \mathrm{dl}$ ) prior to delivery while $40 \%$ had mild anemia ( $\mathrm{Hb} 9.0$ to $10.8 \mathrm{~g} / \mathrm{dl}$ ) and $23 \%$ had moderate anemia ( $\mathrm{Hb} 7$ to $8.9 \mathrm{~g} / \mathrm{dl}$ ). Poor diet was found as the main reason of anemia (Figure 1).

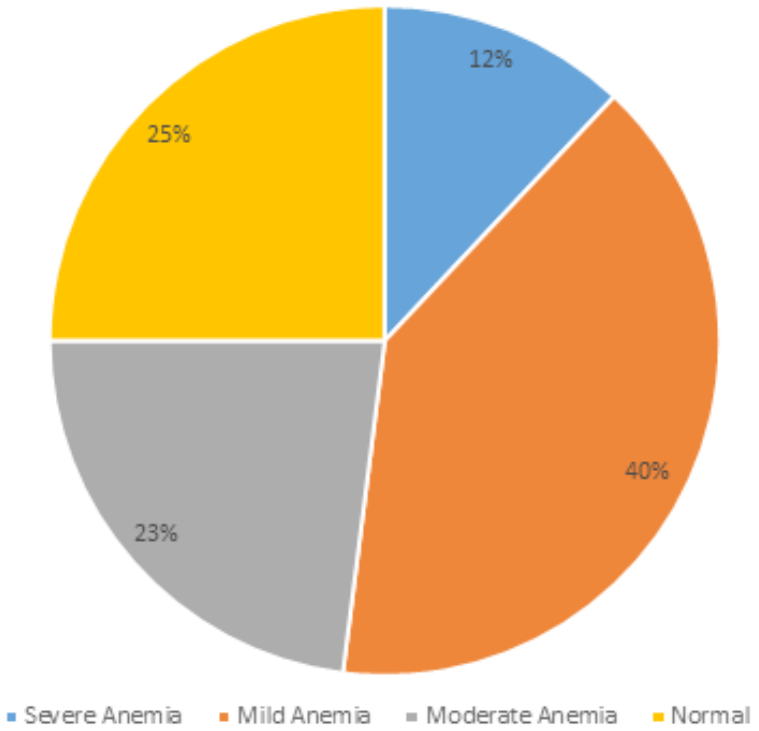

Figure I Frequency of Anemia.

\section{COVID- 19}

Covid-19 was detected in $12 \%$ of the studied women. Affected women were kept in isolation ward for 15 days (Figure 2).

\section{Hepatitis B virus and hepatitis $\mathbf{C}$ virus}

After analyzing the samples on both PCR and ELISA, 3\% of the selected participants were tested positive for HBS-Ag and $2 \%$ were observed as HCV positive. The untreated Hepatitis B infection cause liver cirrhosis, acute renal failure in pregnant women (Figure 3).

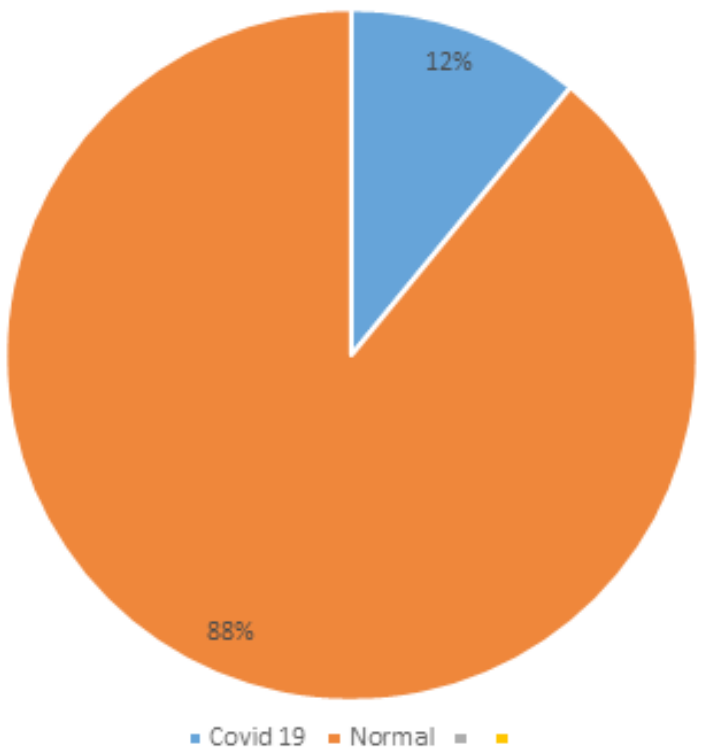

Figure 2 Frequency of Covid-19.

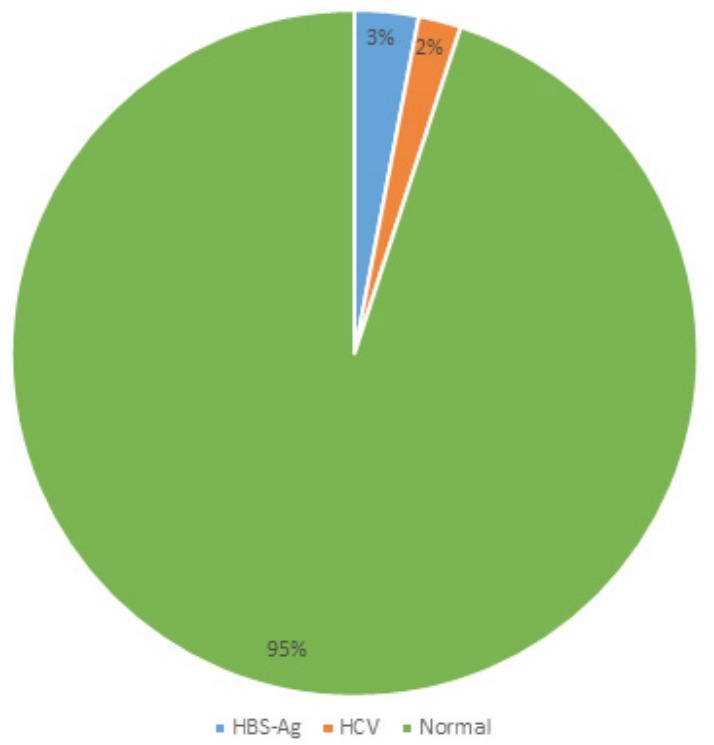

Figure 3 Frequency of HBS and HCV.

\section{Blood sugar (RBS)}

During the current work, 10 percent of the women had higher blood sugar level (RBS 190mg/dl). Most of them having higher level of blood sugar (RBS) were above 40 years of age as well as had a high body mass index (BMI). The reason behind high sugar level was overeating and taking of foods that have greater amount of sugar contents in pregnant women of Swat. The neonates also have a high blood sugar level transmitted from mother through placenta (Figure 4).

\section{Urine R/e (Urine routine examination)}

$\mathbf{3 5 \%}$ of the studied women had a urinary tract infection (UTI). The test reports indicated high amount of pus cells (pus cells 15---20) and Red blood cells (RBCs). The untreated UTI caused full body infection in pregnant women called sepsis (Figure 5). 


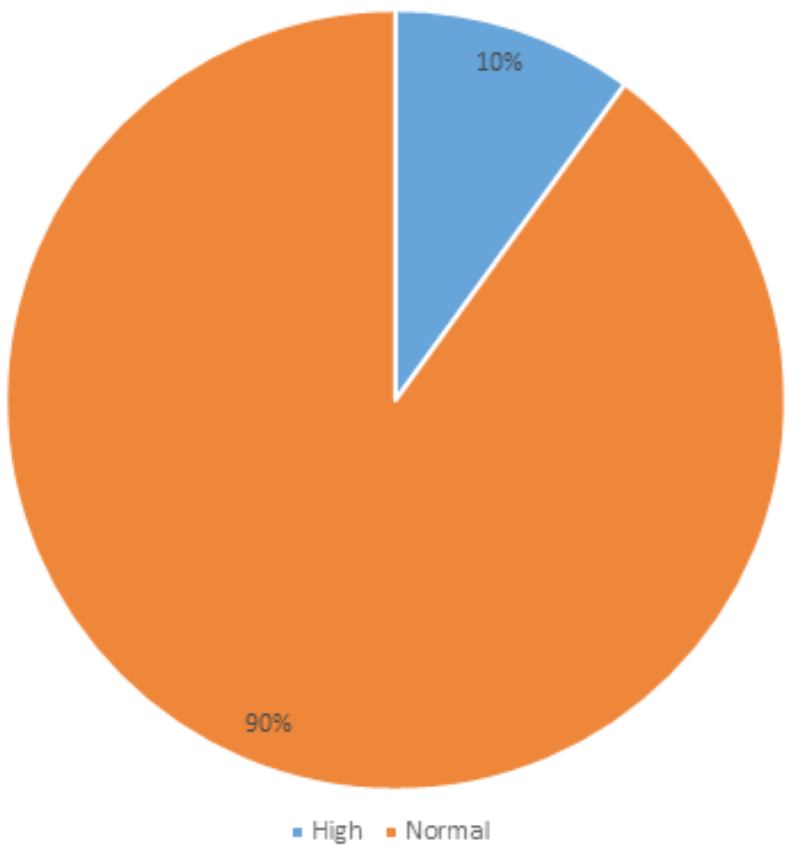

Figure 4 Frequency of blood sugar level.

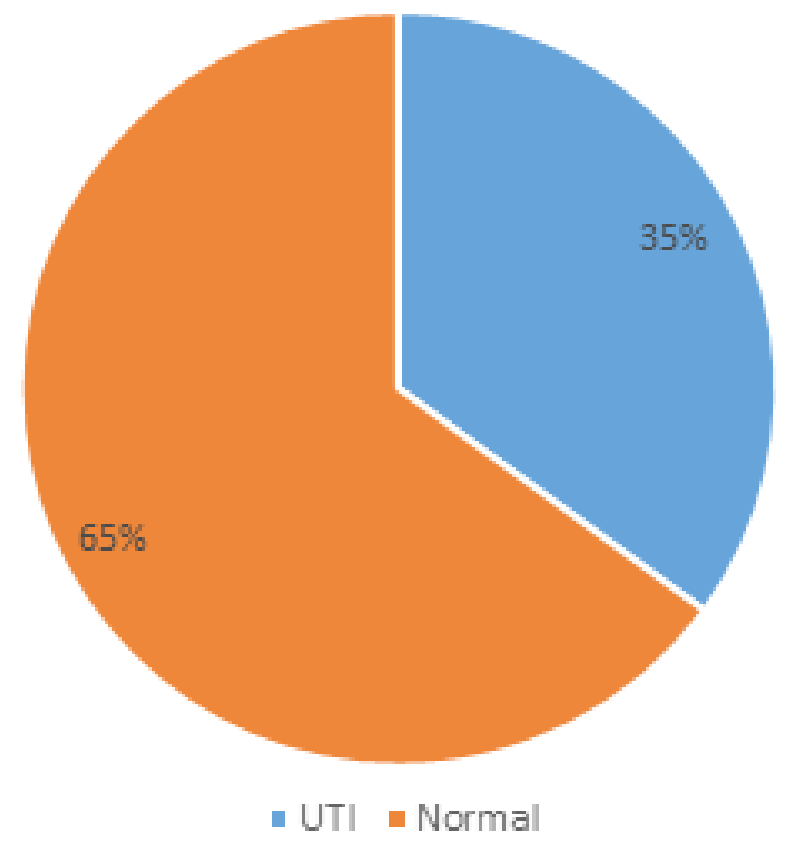

Figure 5 Frequency of UTI.

\section{Brucellosis}

Only $1 \%$ of the participant was found to be effected by brucella. Most of the suffered women belonged to the urban areas of district Swat. These women were very closed to the domestic animals (cows, Goats, buffalos) in their perspective home. The untreated brucellosis cause arthritis, infection of the spleen, liver and central nervous system including meningitis and encephalitis in pregnant women (Figure 6).

\section{Malarial parasites}

Malarial parasite was found in almost 5\% of the examined participants. Most of the malarial patients (having placental malaria) were also HIV positive. The effected women mostly belong to urban areas of swat. Untreated malaria causes cerebral malaria in pregnant women and also effect the new born baby. In pregnant women malaria parasites damage red blood cells which can cause severe anemia (Figure 7).

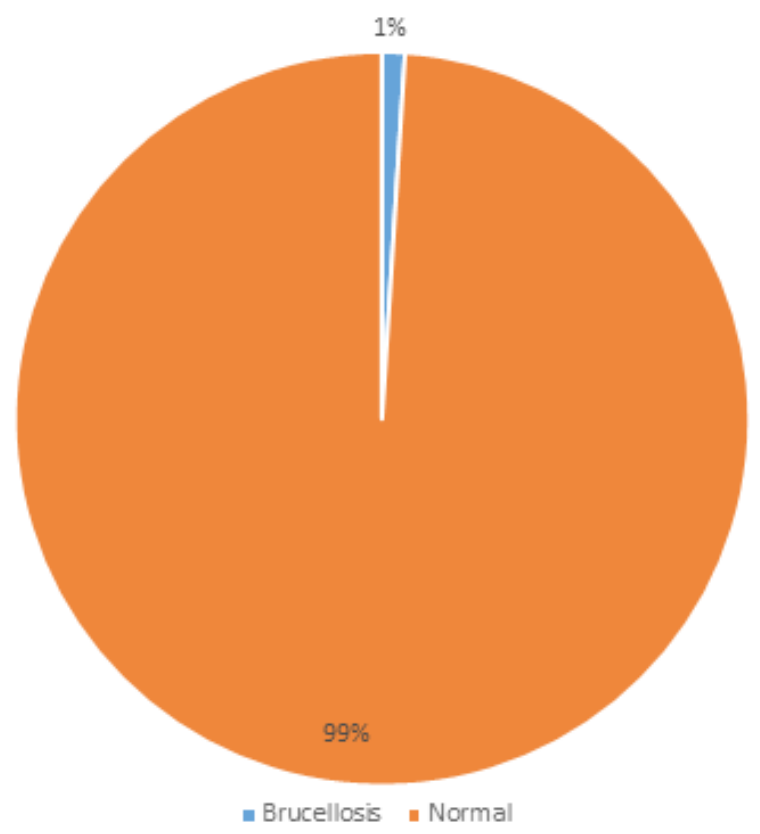

Figure 6 Frequency of Brucellosis.

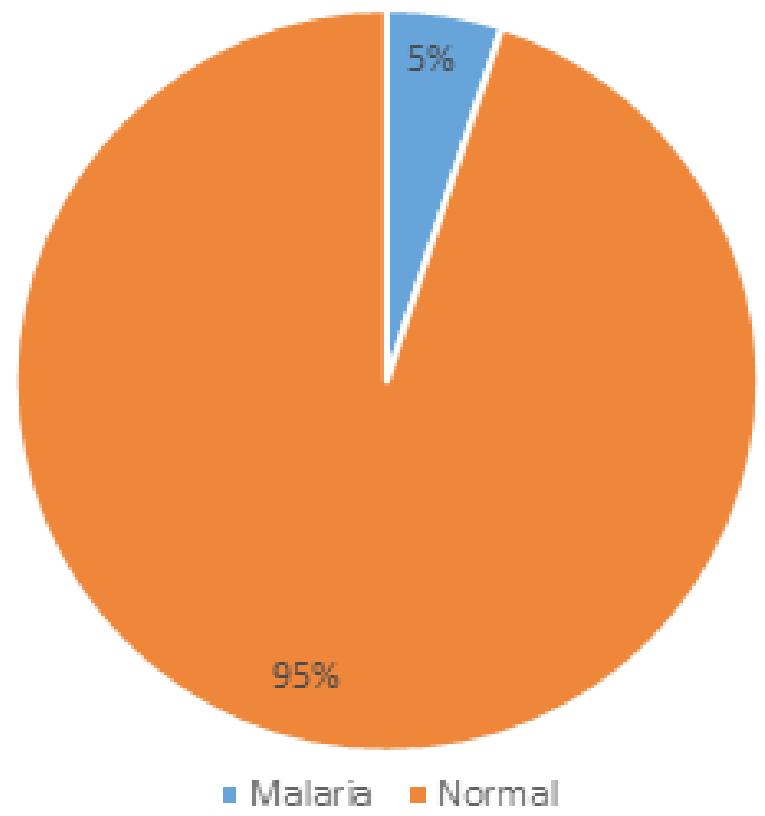

Figure 7 Frequency of Malaria.

\section{Human immune defeciency virus (HIV)}

HIV was rare and detected in only $1 \%$ of the examined one hundred women. These HIV effected women were mostly not the local inhabitants of the district but migrated from other districts here. Furthermore, it was also noted that all of the HIV effected women were currently living in the populated city, Mingora. The HIV infection is contagious through sexually intercourse (Figure 8). 


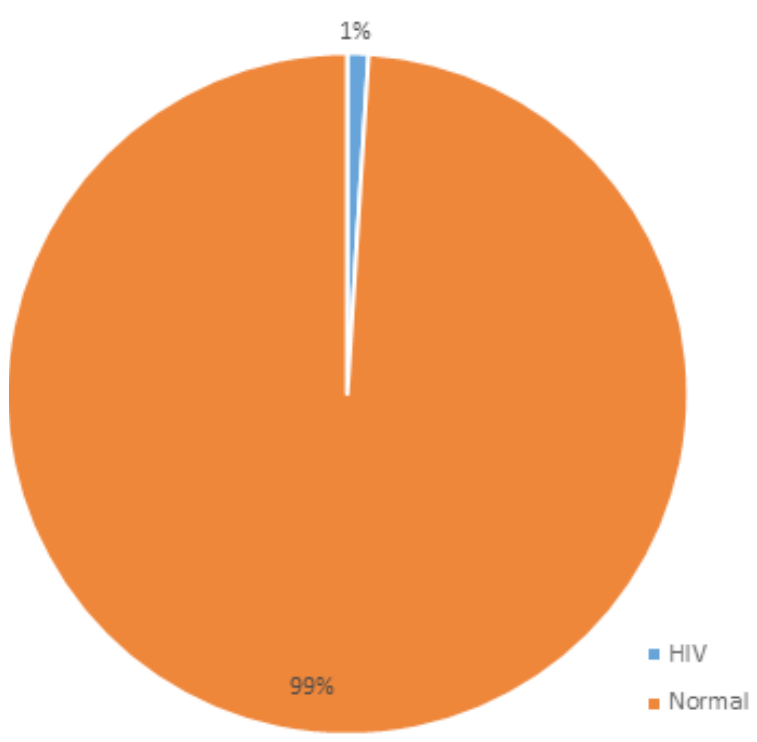

Figure 8 Frequency of HIV.

\section{Discussion}

The present study was conducted in Swat valley of Pakistan. This was the first study of its own kind in the area. Not even a single study was reported prior to our research. Several studies are performed on related topics with following outcomes. Wang et al., stated that deficiency of Vitamin B12 is not common in pregnancy. ${ }^{7}$ Associated with few complications, it happens in $10-28 \%$ of uncomplicated pregnancies. In our research study $12 \%$ of the participants were severe anemic, due to iron and folic acid deficiency and $40 \%$ of the studied women were moderate anemic. Sylvén et al., indicated that Postpartum depression (PPD) is a common childbirth complication, which effects both the newly delivered woman and her child adversely. $35 \%$ of the studied participants had a urinary tract infections during 3rd trimester of pregnancy the untreated urinary tract infection cause full body infection in both mother as well in new born babies. ${ }^{8}$ Bakari et al noted in a research study that obesity is the most common risk factor in the pathogenesis of type- 2 diabetes in cross sectional studies. In our research study $10 \%$ of the pregnant women had high blood sugar (RBS 190mg/dl). ${ }^{9}$ Most of them have a high body mass index (BMI), which cause obesity and diabetes in pregnant women. Brown et al., highlighted that pregnant women are more vulnerable to malaria, which cause severe adverse effects including abortion, low birth weight and maternal anemia. ${ }^{10}$ In the current research study malarial parasite was found in $5 \%$ of the examined participants. Most the affected women having placental malaria. ${ }^{11}$ The untreated malarial parasite causes cerebral malaria in pregnant women and also affect the health of the new born baby. In pregnant women the malaria parasite destroyed the Red blood cells which causes severe anemia. However, no research is reported on the same topic in the same study area. ${ }^{12}$

\section{Conclusion}

From the recent study it was concluded that pregnant women in District Swat KPK Pakistan are susceptible to many diseases and complications. It was found that $12 \%$ women were severe anemic while $23 \%$ were moderate anemic and $40 \%$ were mild anemic. Covid-19 was detected in $12 \%$ of the studied women. $2 \%$ were observed as HCV positive. $10 \%$ of the women had higher blood sugar level (RBS $190 \mathrm{mg} / \mathrm{dl}$ ). $35 \%$ of the studied women had a urinary tract infection (UTI). Only $1 \%$ of the participant was found to be effected by Brucella bacteria. Malarial parasite was found in almost $5 \%$ of the examined participants. HIV was rare and detected in only 0.5 percent of the examined one hundred women.

\section{Recommendations}

Further research in the study area is recommended because not only in District Swat but in entire Pakistan no research study is reported. Moreover, looking at the susceptibilities and risk factors involving pregnancies different seminar, symposiums and conferences should be arranged in order to aware the people of the area.

\section{Acknowledgments}

None.

\section{Conflicts of interest}

None.

\section{Funding}

None.

\section{References}

1. Aaron E, Levine Monahan ABK, Biondo CP. A rapid HIV testing program for labor and delivery in an inner-city teaching hospital. The AIDS Reader. 2006;16(1):1-22.

2. Bakari AG, Onyemelukwe GC, Sani BG, et al. Daignostic test for pregnancy in hospital. Departments of Medicine, Ahmadu Bello University Teaching Hospital, Zaria, Nigeria. 2006:1-150.

3. Bart PA, Jacquier P, Zuber PLF, et al. Seroprevalencc of HBV (anti$\mathrm{HBc}, \mathrm{HBsAg}$ and anti-HBs) and HDV infections among 9006 women at delivery. Liver. 1996:16(2):110-116.

4. Brown, RS, McMahon BJ, Lok ASF, et al. Antiviral therapy in chronic hepatitis B viral infection during pregnancy: A systematic review and meta-analysis. Hepatology. 2016;63(1):319-333.

5. Craig AM, Dotters-Katz S, Kuller JA, et al. Listeriosis in Pregnancy: A Review. Obstet Gynecol Surv. 2019:74(6):362-368.

6. McGregor IA. Epidemiology, malaria and pregnancy. Am J Trop Med Hyg. 1984;33(4):517-525.

7. Nosten F, Kuile TFO, Maelankirri L, et al. White NJ: Malaria during pregnancy in an area of unstable endemicity. Trans $R$ Soc Trop Med Hyg. 1991;85(4):424-429.

8. Puopolo KM, Lynfield R, Cummings JJ. Committee On Fetus And Newborn; committee on infectious diseases. Pediatrics. 2019;144(2):e20191881.

9. Sylvén SM, Elenis E, Michelakos T, et al. Thyroid function tests at delivery and risk for postpartum depressive symptoms. Psychoneuroendocrinology. 2013;38(7):230-234.

10. Wang Z, Tao X, Liu S, et al. An update review on listeria infection in pregnancy. Infect Drug Resist. 2021;14:1967-1968.

11. Wang H, Gao Y, Wu B. Drug therapy strategies for COVID-19 infection during pregnancy. Int J Clin Pharmacol Ther. 2001;59(3):175-181.

12. Wang $\mathrm{P}$, Chen $\mathrm{Y}$, Wang $\mathrm{H}$, et al. A clinical analysis of 16 patients with maternal listeriosis. Zhonghua Nei Ke Za Zhi. 2001;54(9):175-181. 